\title{
Reflexiones en torno a la II edición del Máster en Arquitectura y Patrimonio Histórico
}

Desde enero de 1998 y hasta julio de 1999 se han desarrollado las clases de la segunda edición del Máster en Arquitectura y Patrimonio Histórico. La continuidad en la colaboración entre la Universidad de Sevilla y la Consejería de Cultura se ha materializado nuevamente en el espacio de la docencia y la investigación, en el marco de la transmisión y producción del conocimiento. Éste es un terreno característico del mundo universitario, pero también lo es del Instituto Andaluz del Patrimonio Histórico, que cada día se afianza más en ello gracias a la articulación, por ejemplo, de las diversas actividades de formación que promueve.

La financiación recibida de la Consejería a través del IAPH permite rebajar sustancialmente la matrícula, y junto con las seis becas universitarias (dos completas y dos medias) y las seis ayudas -también del IAPH- para los que se desplazan desde domicilios a más de $60 \mathrm{~km}$. de Sevilla, permiten que estos estudios sean accesibles a un amplio espectro de profesionales, docentes y técnicos de las administraciones públicas. $Y$ que la trayectoria cubierta hasta la fecha, desde que a principios de 1995 se gestó este Proyecto Docente, nos permite registrar una demanda que anima a la definición de la próxima edición.

Si el prestigio cada vez más consolidado y difundido del Instituto que ampara estos estudios genera expectación en torno a las actividades formativas que promueve, entenderemos las obligaciones contraídas por este Máster. Como punto de partida, la asunción de un alumnado extraordinariamente heterogéneo -en esta edición se registran alumnos de ocho diferentes titulaciones o especialidades, en un colectivo de cuarental-, al que hacer partícipe de un mismo marco docente, de asumir ya con la pedagogía de la primera práctica un lenguaje común desde el que decir cosas distintas. Cuestión que va también unida a un no menos variado elenco de profesores, que alcanza a once titulaciones para un total de noventa y ocho docentes ${ }^{2}$.

\section{Docencia y acción patrimonia}

Al Máster que nos cabe en suerte instrumentar, le ha correspondido la implementación de una fuerte dosis de interdisciplinariedad en la propia dinámica de trabajo, cuyo origen radica en la evolución que viene experimentando la acción patrimonial sobre los bienes inmuebles. Que se basa, por tanto, en cambios que tienen que ver -entre otros aspectos- con:

- La asunción de la integralidad de la tutela desde la definición y consideración cada vez más compleja del bien cultural y su envolvente material e inmaterial.

- Las transformaciones vividas en el terreno conceptual e instrumental de las disciplinas convocadas.

- Los propósitos de resolver cuestiones como el solape de administraciones establecidas sobre diferentes ámbitos y escalas, o generadas desde las más diversas lógicas sectoriales.

- Las aspiraciones depositadas y los requerimientos demandados por una sociedad en transformación permanente, cada vez más plural, en suma, por los detentadores de Patrimonio Histórico.

Todo ello proyectado en definitiva sobre territorios patrimoniales cada vez más amplios que rompen a la postre con el tratamiento objetual y mecánico de nuestro patrimonio.

En esta segunda edición del Máster en Arquitectura y Patrimonio Histórico que ahora finaliza se ha consolidado una tendencia presente ya en la primera edición. La fuerte carga experimental de estos estudios, que de alguna manera desafían la enseñanza tradicional de la Escuela de Arquitectura y de las Facultades y Escuelas que nutren al resto de las disciplinas presentes en el Máster, hace que se genere una docencia y una práctica diferente, cuyos resultados muestran un avance rotundo respecto al marco disciplinar del que se parte 3 .

El Máster se abre así al nivel de la investigación -ya no el de la mera reproducción, sino el de la producción de conocimientos- por cuanto los resultados de las propuestas de los módulos de proyectos -que actúan como puntas de lanza en este proceso- han alcanzado un nivel de elaboración que desborda tanto los presupuestos de partida como el marco administrativo donde se inscribe la propia práctica.
Se ha creado un horizonte de expectativas que trasciende el ámbito docente y reclama una incardinación social y administrativa que debe encontrar en el seno del propio Instituto Andaluz del Patrimonio Histórico su continuidad; ya no como práctica ligada al laboratorio, sino como acción patrimonial plena. Estaríamos así en un proceso de realimentación que hace productiva la experiencia del Máster, más allá de la formación especializada de profesionales.

Con todo ello se pone de manifiesto la idoneidad del diseño del marco docente, el esfuerzo mancomunado de Universidad y Consejería, pero también la insuficiencia del propio ámbito para la puesta en desarrollo de las aportaciones más productivas para la resolución de determinados problemas del Patrimonio Histórico y de las disciplinas comprometidas en este campo.

Eduardo Mosquera Adell José Ramón Moreno Pérez

Directores del Máster

\section{Notas}

I. Además de Arquitectura, las especialidades del alumnado son Arqueología, Historia General, Historia del Arte, Antropología, Derecho, Restauración de Bienes Muebles y Arquitectura Técnica.

2. Hay 53 arquitectos, 22 arqueólogos, 9 historiadores del Arte, 3 licenciados en Filosofía, 2 antropólogos, 2 geógrafos, 2 geólogos, 2 restauradores de Bienes Muebles, I licenciado en Derecho, I químico y | ingeniero industrial.

3. Los resortes utilizados en esta ocasión han sido, como punto de partida para las diferentes prácticas, el ex-convento de San Agustín en Sevilla, el conjunto arqueológico de Madinat al-Zahra y el ámbito de su Plan Especial de Protección y, finalmente, Antequera y su encuadre territorial. 